\title{
Sosialisasi Buku Kia Versi 2020 Bagi Kader di Desa Cikunir Kecamatan Singaparna Kabupaten Tasikmalaya Tahun 2021
}

\author{
Fenty Agustini, Tupriliany Danefi \\ Sekolah Tinggi Ilmu Kesehatan Respati \\ Fentyagustini86@gmail.com
}

\begin{abstract}
Abstrak
Kabupaten Tasikmalaya merupakan daerah dengan angka kematian ibu tertinggi ke-3 di Jawa Barat, pada tahun 2016 Angka Kematian Ibu di Kabupaten Tasikmalaya adalah 145,23/100.000 KH dan angka kematian bayi tertinggi ke-4 yaitu pada tahun 2016 sebesar 8,23/1000 KH. Berdasarkan data pendahuluan yang diperoleh dari kader Desa Cikunir didapatkan hasil bahwa sebagian besar buku KIA disimpan di posyandu dengan alasan biar tidak rusak sehingga sebagian besar ibu tidak memahami isi yang terdapat didalam buku KIA. Tujuan kegiatan pengabdian kepada masyarakat ini adalah untuk Sosialisasi Buku KIA Versi 2020 Bagi Kader di Desa Padasuka Kecamatan Sukarame Kabupaten Tasikmalaya Tahun 2021. Kegiatan pengabdian kepada masyarakat ini dilaksanakan dalam bentuk sosialisasi Buku KIA Versi 2020 Bagi Kader di Desa Cikunir Kecamatan Singaparna Kabupaten Tasikmalaya Tahun 2021. Dengan terlebih dahulu dilakukan pre test dan setelah dilakukan sosialisasi dilaksanakan post test untuk mengukut sejauh mana efektivitas pelaksanaan sosialisasi. Sasaran sosialiasi kader adalah kader di Desa Cikunir Wilayah Kerja Puskesmas Singaparna berjumlah 12 orang yaitu perwakilan kader setiap posyandu. Dari 12 orang kader, sebanyak 10 orang $(83,3 \%)$ mengalami kenaikan nilai dari pre test dan post test sedangkan 2 orang $(16,7 \%)$ memiliki nilai yang tetap. Berdasarkan hasil kegiatan tersebut dapat disimpulkan bahwa kegiatan sosialisasi cukup efektif untuk meningkatkan pengetahuan kader.
\end{abstract}

Kata kunci : Sosialisasi, Buku KIA, Kader

\section{Abstract}

Tasikmalaya is the area with the 3rd highest maternal mortality rate in West Java, in 2016 the Maternal Mortality Rate in Tasikmalaya Regency was 145.23/100,000 KH and the 4th highest infant mortality rate in 2016 was $8.23 / 1000 \mathrm{KH}$. Based on preliminary data obtained from Cikunir Village cadres, it was found that most of the $\mathrm{MCH}$ books were kept in the posyandu with the reason that they would not be damaged so that most of the mothers did not understand the contents of the $\mathrm{MCH}$ handbook. The purpose of this community service activity is to disseminate the 2020 version of the $\mathrm{MCH}$ Book for Cadre in Padasuka Village, Sukarame District, Tasikmalaya in 2021. This community service activity is carried out in the form of socializing the $2020 \mathrm{MCH}$ Book for Cadre in Cikunir Village, Singaparna District, Tasikmalaya in 2021. First, a pre-test is carried out and after the socialization, a post-test is carried out to measure the effectiveness of the implementation of the socialization. The target of cadre socialization is cadres in Cikunir Village, Singaparna Health Center Work Area, totaling 12 people, namely cadres representatives from each posyandu. Of the 12 cadres, as many as 10 people (83.3\%) experienced an increase in the value of the pre test and post test while 2 people $(16.7 \%)$ had a fixed score. Based on the results of these activities, it can be concluded that socialization activities are quite effective in increasing the knowledge of cadres.

Keywords: Socialization, MCH Handbook, Cadre

http://ejournal.urindo.ac.id/index.php/PAMAS 


\section{PENDAHULUAN}

Target AKI Indonesia sesuai SDGs (Sustainable Development Goals) 2030 adalah mengurangi AKI hingga di bawah 70 per 100.000 kelahiran hidup, menurunkan Angka Kematian Neonatal hingga 12 per $1000 \mathrm{KH}$ dan Angka Kematian Balita 25 per $1000 \mathrm{KH}$. Untuk mencapai target tersebut perlu upaya percepatan yang lebih besar dan kerjasama antara tenaga kesehatan.

Kebijakan dan berbagai upaya pemerintah untuk menurunkan angka kematian ibu dan bayi, antara lain dengan Gerakan Sayang Ibu (GSI), Strategi Making Pregnancy Safer dan pengadaan buku Kesehatan Ibu dan Anak [1]. Buku KIA adalah alat untuk mendeteksi secara dini adanya gangguan atau masalah kesehatan ibu dan anak, alat komunikasi dan penyuluhan dengan informasi yang penting bagi ibu, keluarga dan masyarakat mengenai pelayanan, kesehatan ibu dan anak termasuk rujukannya dan pekat (standar) pelayanan KIA, gizi, imunisasi, dan tumbuh kembang balita [2].

Salah satu faktor penyebab tidak langsung dari kematian ibu yaitu terlambat mengetahui tanda bahaya kehamilan. Untuk dapat mengantisipasi hal tersebut maka diperlukan suatu upaya untuk dapat mengenali komplikasi kehamilan atau tanda bahaya kehamilan. Salah satunya adalah dengan pemanfaatan buku KIA yang didalamnya berisi informasi tentang tanda bahaya kehamilan. Untuk dapat mengenali tanda bahaya kehamilan maka ibu hamil perlu diberikan pengetahuan agar dapat bersikap positif dan agar dapat melakukan tindakan yang tepat saat menemui tandatanda bahaya kehamilan [3].

Buku KIA merupakan sebuah buku program secara nasional yang berisi informasi dan materi penyuluhan tentang gizi, kesehatan ibu dan anak, kartu ibu hamil, KMS Balita dan catatan pelayanan kesehatan ibu dan anak. Buku KIA disimpan di rumah dan dibawa setiap kali ibu dan anak datang ke Posyandu. Setiap ibu hamil mendapatkan satu buku KIA dan digunakan sampai anak berusia lima tahun. Dengan buku KIA kondisi kesehatan ibu dan anak dapat dicatat serta berisi informasi tentang kesehatan, sehingga perkembangan balita dapat terpantau berdasarkan catatan yang ada dalam buku KIA.

Buku Kesehatan Ibu dan Anak (Buku KIA) selalu diperbaharui menyesuaikan dengan informasi terkini setiap tahunnya dengan perubahan total setiap lima tahun. Berdasarkan Keputusan Menteri Kesehatan Nomor 284/Menkes/SK/III/2004 tentang Buku Kesehatan Ibu dan Anak menetapkan bahwa Buku KIA merupakan satu-satunya alat pencatatan pelayanan kesehatan ibu dan anak sejak ibu hamil, melahirkan dan selama nifas, hingga bayi yang dilahirkan berumur 5 tahun, termasuk pelayanan KB, imunisasi, gizi dan tumbuh kembang anak. Buku KIA dapat diperoleh pada Polindes, Puskesmas Pembantu (Pustu), Puskesmas, rumah sakit, tempat praktik bidan, dokter, dokter spesialis obstetri dan ginekologi, dokter spesialis anak serta sarana pelayanan kesehatan lainnya milik Pemerintah atau Swasta. Pengadaan dan pendistribusian buku merupakan tanggungjawab pemerintah yang bisa dikerjasamakan dengan Lembaga Swadaya Masyarakat, Organisasi Profesi dan dunia usaha. Jumlah buku disesuaikan dengan jumlah sasaran ibu hamil di wilayah tertentu dan harus sesuai dengan warna, 
format serta isi Buku KIA yang dikeluarkan Kementerian Kesehatan. Pada tanggal 11 Juni 2020 telah dilakukan Sosialisasi Buku KIA Revisi 2020 melalui Zoom Meeting dan Channel YouTube Direktorat Kesehatan Keluarga.

Saat ini persebaran buku KIA di Indonesia sudah mencapai 94\%. Akan tetapi meskipun data survei kesehatan nasional [4] menunjukkan sebanyak $81,5 \%$ ibu hamil telah memiliki buku KIA, hanya 60,5\% di antaranya yang bisa menunjukkan dan hanya sebanyak $18 \%$ buku KIA yang terisi lengkap. Berdasarkan hal tersebut peneliti tertarik untuk melakukan penelitian tentang hubungan pemanfaatan buku KIA dengan pengetahuan ibu hamil tentang tanda bahaya kehamilan. Kabupaten Tasikmalaya merupakan daerah dengan angka kematian ibu tertinggi ke-3 di Jawa Barat, pada tahun 2016 Angka Kematian Ibu di Kabupaten Tasikmalaya adalah 145,23/100.000 KH dan angka kematian bayi tertinggi ke-4 yaitu pada tahun 2016 sebesar 8,23/1000 KH. Berdasarkan data pendahuluan yang diperoleh dari kader Desa Cikunir didapatkan hasil bahwa sebagian besar buku KIA disimpan di posyandu dengan alasan biar tidak rusak sehingga sebagian besar ibu tidak memahami isi yang terdapat didalam buku KIA. Berdasarkan hal tersebut diperlukan sosialisasi lebih lanjut terkait dengan Buku KIA versi 2020 untuk mengoptimalkan pemanfaatan buku KIA.

\section{METODE}

Kegiatan pengabdian kepada masyarakat ini dilaksanakan dalam bentuk sosialisasi Buku KIA Versi 2020 Bagi Kader di Desa Cikunir Kecamatan Singaparna Kabupaten Tasikmalaya Tahun 2021. Dengan terlebih dahulu dilakukan pre test dan setelah dilakukan sosialisasi dilaksanakan post test untuk mengukut sejauh mana efektivitas pelaksanaan sosialisasi. Sasaran sosialiasi kader adalah kader di Desa Cikunir Wilayah Kerja Puskesmas Singaparna berjumlah 12 orang yaitu perwakilan kader setiap posyandu.

\section{HASIL DAN PEMBAHASAN}

\section{a. Hasil Kegiatan}

Kegiatan pengabdian kepada masyarakat dilakukan dengan hasil sebagai berikut :

1) Umur

Tabel Distribusi Sasaran Berdasarkan Umur

\begin{tabular}{c|cc}
\multicolumn{1}{c}{ Umur } & Jumlah & Persentase (\%) \\
\hline$<20$ Tahun & 0 & 0 \\
$20-35$ Tahun & 5 & 41,7 \\
$>35$ Tahun & 7 & 58,3 \\
Total & $\mathbf{1 2}$ & $\mathbf{1 0 0}$
\end{tabular}


Berdasarkan tabel diatas dapat disimpulkan bahwa sebagian besar sasaran berada pada kisaran umur $>35$ tahun yaitu sebanyak 7 orang atau $58,3 \%$.

2) Pendidikan

Tabel Distribusi Sasaran Berdasarkan Pendidikan

Pendidikan

$S D$

SMP

SMA

PT

Total
Jumlah

1

2

8

1

12
Persentase (\%)

16,6

66,8

8,3

100

Berdasarkan tabel diatas dapat disimpulkan bahwa sebagian besar sasaran berpendidikan SMA yaitu sebanyak 8 orang atau $66,8 \%$.

3) Pekerjaan

Tabel Distribusi Sasaran Berdasarkan Pekerjaan

\begin{tabular}{c|cc} 
Pekerjaan & Jumlah & Persentase (\%) \\
\hline Bekerja & 2 & 16,7 \\
IRT & 10 & 83,7 \\
Total & 12 & 100
\end{tabular}

Berdasarkan tabel diatas dapat disimpulkan bahwa sebagian besar sasaran sebagai Ibu Rumah Tangga yaitu sebanyak 10 orang atau $83,7 \%$.

4) Lama Menjadi Kader

Tabel Distribusi Sasaran Berdasarkan Lama Menjadi Kader

\begin{tabular}{c|cc}
\multicolumn{1}{c}{ Lama } & Jumlah & Persentase (\%) \\
\hline$<1$ tahun & 0 & 0 \\
1-3 Tahun & 4 & 33,3 \\
4-5 Tahun & 2 & 16,7 \\
$>5$ Tahun & 6 & 50 \\
Total & $\mathbf{1 2}$ & $\mathbf{1 0 0}$
\end{tabular}

Berdasarkan tabel diatas dapat disimpulkan bahwa sebagian besar sasaran memiliki pengalaman menjadi kader lebih dari 5 tahun yaitu sebanyak 6 orang atau $50 \%$. 


\section{5) Hasil Pre dan Post Test}

Berikut hasil pre test dan post tes yang dilakukan sebelum dan sesudah sosialisasi dengan hasil sebagai berikut :

Tabel Hasil Pre dan Post Test

\begin{tabular}{c|cc|} 
Responden & Nilai Pre Test & Nilai Post Test \\
\hline 1 & 7 & 10 \\
2 & 5 & 9 \\
3 & 5 & 9 \\
4 & 5 & 10 \\
5 & 6 & 10 \\
6 & 6 & 9 \\
7 & 7 & 10 \\
8 & 5 & 8 \\
9 & 7 & 7 \\
10 & 5 & 9 \\
11 & 7 & 10 \\
12 & 7 & 7 \\
\end{tabular}

Berdasarkan hasil tersebut dapat disimpulkan bahwa dari 12 orang kader, sebanyak 10 orang $(83,3 \%)$ mengalami kenaikan nilai dari pre test dan post test sedangkan 2 orang $(16,7 \%)$ memiliki nilai yang tetap.

\section{b. Pembahasan}

Berdasarkan hasil tersebut dapat disimpulkan bahwa dari 12 orang kader, sebanyak 10 orang $(83,3 \%)$ mengalami kenaikan nilai dari pre test dan post test sedangkan 2 orang $(16,7 \%)$ memiliki nilai yang tetap.

Sesuai dengan teori [5] penyuluhan kesehatan adalah kegiatan yang dilakukan untuk penambahan pengetahuan dan kemampuan seseorang melalui tehnik praktik belajar atau instruksi dengan tujuan mengubah atau mempengaruhi perilaku manusia secara individu, kelompok maupun masyarakat untuk dapat lebih mandiri dalam mencapai tujuan hidup sehat.

Dari 12 orang kader, sebanyak 10 orang $(83,3 \%)$ mengalami kenaikan nilai dari pre test dan post test sedangkan 2 orang (16,7\%) memiliki nilai yang tetap. Menurut [6] pengetahuan adalah hasil pengindraan manusia, atau hasil tahu seseorang terhadap objek melalui indra yang dimilikinya (mata, hidung, telinga, dan sebagainya). Dengan sendirinya, pada waktu pengindraan sampai menghasilkan pengetahuan tersebut sangat dipengaruhi oleh intensitas perhatian dan 
persepsi terhadap objek. Sebagian besar pengetahuan seseorang diperoleh melalui indra pendengaran yaitu telinga dan indra penglihatan yaitu mata Setiap kegiatan yang dilakukan umumnya memberi manfaat. Pengetahuan merupakan upaya manusia yang secara khusus dengan objek tertentu, terstruktur, tersistematis, menggunakan seluruh potensi kemanusiaan dan dengan menggunakan metode tertentu. Pengetahuan merupakan sublimasi atau intisari dan berfungsi 5 sebagai pengendali moral dari pada pluralitas keberadaan ilmu pengetahuan [7].

Berdasarkan hasil pengambilan data diperoleh bahwa umur ibu hamil sebagian besar berada pada rentang usia $>35$ tahun yaitu sebanyak 7 orang $(58,3 \%)$, hal ini sesuai dengan teori menurut [6] bahwa pengetahuan yang dimiliki oleh seseorang dapat dipengaruhi oleh beberapa faktor yaitu umur, umur sangat berpengaruh pada pengetahuan semakian tua umur seseorang maka proses perkembangan mentalnya bertambah baik. Umur yang cukup memiliki pola pikir dan pengalaman yang matang sehingga pengetahuan yang diperolehnya semakin baik. Dengan bertambahnya umur seseorang akan terjadai perubahan pada aspek psikis dan psikologis (mental). Pertumbuhan fisik secara garis besar akan mengalami perubahan baik dari aspek ukuran maupun dari aspek proporsi yang mana hal ini terjadi akibat pematangan fungsi organ. Sedangkan pada aspek psikologis (mental) terjadi perubahan dari segi taraf berfikir seseorang yang semakin matang dan dewasa. Selain itu, semakin bertambah usia maka semakin banyak pengalaman dan pengetahuan yang di peroleh oleh seseorang, sehingga bisa meningkatkan kematangan mental dan intelektual. Usia seseorang yang lebih dewasa mempengaruhi tingkat kemampuan dan kematangan dalam berfikir dan menerima informasi yang semakin lebih baik jika di bandingkan dengan usia yang lebih muda. Usia mempengaruhi tingkat pengetahuan sesorang. Semakin dewasa umur maka tingkat kematangan dan kemampuan menerima informasi lebih baik jika di bandingkan dengan umur yang lebih muda atau belum dewasa. Menurut WHO (dikutip dalam [8].

Sesuai besarnya umur, terdapat kemungkinan perbedaan dalam mendapatkan faktor keterpaparan tertentu berdasarkan lamanya perjalanan hidup. Demikian pula dengan karakteristik yang lain yang akan membawa perbedaan dalam kemungkinan mendapatkan kecenderungan terjadinya penyakit dengan bertambahnya usia. Semakin tua seseorang maka semakin peka terhadap penyakit dan semakin banyak keterpaparan yang di alami, karena itu umur meningkat secara ilmiah akan membawa pertambahan resiko suatu penyakit.

Tingkat pendidikan kader sebagian besar SMA yaitu sebanyak 8 orang $(66,8 \%)$ hal ini sesuai dengan teori [6] bahwa Pendidikan merupakan suatu kegiatan proses pembelajaran untuk mengembangkan atau meningkatkan kemampuan tertentu sehingga sasaran pendidikan itu dapat berdiri sendiri. Intelegasi diartikan sebagai suatu kemampuan seseorang untuk belajar 
dan berfikir guna untuk menyesuaikan diri secara mental dalam siatuasi baru. Dengan demikian dapat disimpulkan bahwa perbedaan intelegensi dari seseorang akan berpengaruh pula terhadap tingkat pengetahuan. Selain faktor diatas faktor lain yang mempengaruhi pengetahuan seseorang adalah lingkungan. Lingkungan merupakan salah satu faktor yang mempengaruhi pengetahuan seseorang. Seseorang dapat mempelajari hal-hal yang baik dan juga hal-hal buruk tergantung pada sifat kelompoknya. Social budaya memiliki pengaruh pada pengetahuan seseorang, suatu kebudayaan dalam hubungannya dengan orang lain karena dengan hubungan ini seseorang mengalami proses belajar dan memperoleh suatu pengetahuan dari adat istiadat social budaya.[6].

Pendidikan berarti bimbingan yang diberikan seseorang kepada orang lain terhadap suatu hal agar mereka dapat memahami. Pendidikan merupakan sebuah proses belajar dan proses pertumbuhan, perkembangan atau perubahan ke arah yang lebih baik, lebih dewasa dan lebih matang terhadap individu, kelompok atau masyarakat Tidak dapat dipungkiri bahwa makin tinggi pendidikan seseoarang semakin mudah pula mereka menerima informasi dan pada akhirnya makin banyak pula pengetahuan yang dimilikinya. Sebaliknya, jika seseorang tingkat pendidikannya rendah, akan menghambat perkembangan sikap seseorang terhadap penerimaan, informasi dan nilai-nilai yang baru diperkenalkan [9]. Adapun selain itu, pendidikan juga merupakan perubahan sikap, tingkah laku dan penambahan ilmu dari seseorang serta merupakan proses dasar dari kehidupan manusia. Melalui pendidikan manusia melakukan perubahan-perubahan kualitatif induvidu sehingga tingkah lakunya berkembang. Semua aktivitas dan prestasi hidup manusia tidak lain adalah hasil dari belajar. Proses belajar tidak akan terjadi begitu saja apabila tidak ada di sertai sesuatu yang menolong pribadi yang bersangkutan [9]

Tingkat pendidikan seseorang atau individu akan berpengaruh terhadap kemampuan berfikir, semakin tinggi tingkat pendidikan akan semakin mudah berfikir rasionalisme dan menangkap informasi baru termasuk dalam menguraikan masalah yang baru. Di harapkan bagi seseorang yang berpendidikan tinggi memiliki pengetahuan yang luas termasuk pengetahuan terhadap kebutuhan kesehatannya. Latar belakang pendidikan dan pengalaman di masa lalu dapat mempengaruhi pola pikir seseorang, kemampuan kognitif akan membentuk cara berfikir seseorang, termasuk membentuk kemampuan untuk mempelajari atau memahami faktor-faktor yang berkaitan dengan penyakit yang di deritanya, dan menggunakan pengetahuan tentang kesehatan dan penyakit yang di milikinya untuk menjaga kesehatan diri. Kemampuan kognitif juga berhubungan dengan tahap perkembangan seseorang [10]

Jenjang pendidikan kader sebagian besar kader sebagai Ibu Rumah Tangga yaitu sebanyak 10 orang atau $83,7 \%$. Pekerjaan merupakan suatu kegiatan atau aktivitas seseorang untuk 
memperoleh penghasilan guna memenuhi kebutuhan hidupnya sehari-hari. Pekerjaan/karyawan adalah mereka yang bekerja pada orang lain atau institusi, kantor, perusahaan dengan upah dan gaji baik berupa uang maupun barang. Lingkungan pekerjaan dapat menjadikan seseorang memperoleh pengalaman dan pengetahuan baik secara langsung maupun tidak langsung. Pekerjaan bukanlah sumber kesenangan, tetapi lebih banyak merupakan cara mencari nafkah yang membosankan, berulang, dan banyak tantangan. Semakin lama seseorang bekerja semakin banyak pengetahuan yang diperoleh [11]. Hal ini tidak sesuai dengan teori yang mengatakan bahwa pekerjaan merupakan faktor yang mempengaruhi pengetahuan. Ditinjau dari jenis pekerjaan yang sering berinteraksi dengan orang lain lebih banyak pengetahuannya bila dibandingkan dengan orang tanpa ada interaksi dengan orang lain. Pengalaman belajar dalam bekerja yang dikembangkan memberikan pengetahuan dan keterampilan profesional serta pengalaman belajar dalam bekerja akan dapat mengembangkan kemampuan dalam mengambil keputusan yang merupakan keterpaduan menalar secara ilmiah dan etik [11]. Penulis berasumsi bahwa dijaman teknologi sekarang walaupun berperan sebagai Ibu Rumah Tangga, dengan mudah informasi bisa didapatkan dengan mudahnya akses internet.

Berdasarkan pembahasan diatas dapat disimpulkan bahwa penyuluhan kesehatan menyebabkan peningkatan pengetahuan bagi ibu hamil, disamping itu terdapat faktor lain yang mempengaruhi pengetahuan seseorang diantaranya umur dan pendidikan ibu hamil.

\section{KESIMPULAN DAN SARAN}

\section{a) Kesimpulan}

Berdasarkan hasil kegiatan tersebut dapat disimpulkan bahwa kegiatan sosialisasi cukup efektif untuk meningkatkan pengetahuan kader.

b) Saran

Saran bagi kader diharapkan kader bisa memahami buku KIA versi 2020 sehingga bisa memanfaatkan dan memberikan edukasi kepada ibu hamil maupun keluarga.

\section{DAFTAR PUSTAKA}

[1] A. Wiratih, "Tingkat Pengetahuan Ibu Hamil Tentang Buku Kesehtan Ibu Dan Anak (KIA) di BPS Titik Desa Padas Kecamatan Tanon Kabupaten Sragen Tahun 2013.," J. Keperawatan., vol. 1, no. 2, 2013.

[2] R. Kementrian Kesehatan, "Riset Kesehatan Dasar (Riskesdas)," Jakarta, 2013.

[3] Suryani, "Hubungan pengetahuan dan status ekonomi dengan status gizi ibu hamil di Puskesmas Putri Ayu Kota Jambi," 2009.

[4] B. P. P. K. K. K. R. SIRKESNAS, "Survei Indikator Kesehatan Nasional," Jakarta, 2016. 
[5] Amanah, "Makna Penyuluhan dan Transformasi Perilaku Manusia," J. Penyul., vol. 3, no. 1, 2007.

[6] S. Notoatmodjo, Ilmu Perilaku Kesehatan. Jakarta: PT Rineka Cipta, 2010.

[7] A. D. Wawan, Teori dan Pengukuran Pengetahuan, Sikap dan Perilaku Manusia. Yogyakarta: Nuha Medika, 2010

[8] Hurlock E.B, Psikologi Perkembangan : Suatu Pendekatan Sepanjang Rentang Kehidupan. Jakarta. Erlangga, 2009.

[9] Soekanto, Sosiologi Suatu Pengantar. Jakarta: CV Rajawali, 2002.

[10] A. . Potter, P.A., dan Perry, Buku Ajar Fundamental Keperawatan: Konsep, Proses, Dan Praktik, 4th ed. Jakarta: EGC, 2005.

[11] Wati, "Pengaruh Penyuluhan Terhadap Peningkatan Pengetahuan," 2009. 